\title{
Brachydactyly-long thumb syndrome
}

INSERM

\section{Source}

INSERM. (1999). Orphanet: an online rare disease and orphan drug data base.

Brachydactyly-long thumb syndrome. ORPHA:2946

Brachydactyly - long thumb syndrome is a very rare autosomal dominant heart-hand syndrome (see this term) that is characterized by bisymmetric brachydactyly accompanied by long thumbs, joint anomalies (restriction of motion at the shoulder and metacarpophalangeal joints) and cardiac conduction defects. Additional features include small hands and feet, clinodactyly, narrow shoulders with short clavicles, pectus excavatum and mild shortness of the limbs, cardiomegaly and murmur of pulmonic stenosis.It has been described in four family members from three generations, with no new cases having been reported since 1981. 